\title{
BROADBAND WIRELESS ACCESS
}




\section{THE KLUWER INTERNATIONAL SERIES}

IN ENGINEERING AND COMPUTER SCIENCE 


\title{
BROADBAND WIRELESS ACCESS
}

\author{
Benny Bing
}

KLUWER ACADEMIC PUBLISHERS

NEW YORK, BOSTON, DORDRECHT, LONDON, MOSCOW 
eBook ISBN: $\quad 0-306-47302-X$

Print ISBN: $\quad$ 0-792-37955-1

(C)2002 Kluwer Academic Publishers

New York, Boston, Dordrecht, London, Moscow

All rights reserved

No part of this eBook may be reproduced or transmitted in any form or by any means, electronic, mechanical, recording, or otherwise, without written consent from the Publisher

Created in the United States of America

Visit Kluwer Online at: and Kluwer's eBookstore at: http://www.kluweronline.com

http://www.ebooks.kluweronline.com 
As always, to my mother 


\section{TABLE OF CONTENTS}

Dedication $\quad$ V

Table of Contents vii

Preface xvii

\section{Chapter 1 Overview of Wireless Networks}

1.1 Signal Coverage 1

1.2 Propagation Mechanisms 2

1.2.1 Multipath 2

1.2.2 Delay Spread 3

1.2.3 Coherence Bandwidth 4

1.2.4 Doppler Spread 5

1.2.5 Shadow Fading 6

1.2.6 Radio Propagation Modeling 6

1.2.7 Narrowband and Wideband Channel Models 6

$\begin{array}{ll}1.3 \text { Signal Attenuation } & 7\end{array}$

1.3.1 Received Power Characteristics $\quad 7$

1.3.2 High Frequency Propagation $\quad 8$

1.4 Channel Characteristics 9

1.4.1 Gaussian Channel 9

1.4.2 Rayleigh Channel 9

1.4.3 Rician Channel 10

1.5 Fading Mitigation Methods 10

1.5.1 Antenna Diversity 11

1.5.2 Equalization 11

1.5.3 Error Control 13

1.5.4 Multicarrier Transmission 13

1.5.5 Orthogonal Frequency Division Multiplexing 14

1.5.6 Wideband Systems

1.6 Interference 15

1.6.1 Cochannel Interference 16

$\begin{array}{ll}\text { 1.6.2 Mitigation Techniques } & 17\end{array}$

$\begin{array}{ll}1.7 \text { Modulation } & 17\end{array}$

$\begin{array}{ll}\text { 1.7.1 Linear versus Constant Envelope } & 17\end{array}$

1.7.2 Coherent versus Non-Coherent Detection 18 
$\begin{array}{ll}\text { 1.7.3 Multicarrier Modulation } & 19\end{array}$

1.8 Signal Duplexing Techniques 20

1.8.1 Spectrum Considerations 20

1.8.2 Radio Design Considerations 20

1.8.3 Implementation Considerations 21

1.9 Mobility and Handoff 21

1.9.1 Intracell versus Intercell Handoff 22

1.9.2 Mobile-Intiated versus Network-Initiated Handoff 22

1.9.3 Forward versus Backward Handoff 23

1.9.4 Hard versus Soft Handoff 23

1.10 Channel Assignment Strategies $\quad 24$

1.11 Synchronization 24

1.12 Power Management 25

1.13 Spectrum Allocation $\quad 25$

Summary 26

$\begin{array}{ll}\text { Bibliography } & 27\end{array}$

\section{Chapter 2 Wireless Access Protocol Design}

2.1 Traffic Source Characterization 31

2.1.1 Periodic Traffic 31

2.1.2 Bursty Traffic 33

2.2 Characterizing Applications 34

2.2.1 Information Types 34

2.2.2 Delivery Requirements $\quad 34$

2.2.3 Symmetry of Connection 35

2.2.4 Communication Requirements

2.2.5 Broadband Services $\quad 35$

2.3 Resource Sharing 36

2.3.1 Resource Sharing Principles 36

2.3.2 The Global Queue $\quad 37$

2.3.3 Measuring Resource Usage 38

2.3.4 Resource Sharing in Wideband Wireless Networks 38

2.3.5 Resource Reservation and Application Adaptation $\quad 39$

2.3.6 Admission Control 39

2.4 Performance Analysis 40

2.5 Performance Evaluation 41

2.5.1 Efficiency $\quad 42$

2.5.2 Throughput $\quad 42$ 
2.5.3 Response Time $\quad 43$

2.5.4 Fairness 43

2.6 Implementation Considerations 43

2.6.1 Centralized versus Distributed Design 43

2.6.2 Mobility versus Portability 44

2.6.3 Integration with Higher Layer Functions 45

Summary $\quad 45$

Bibliography $\quad 45$

\section{Chapter 3 Multiple Access Communications}

3.1 Characterizing the Access Problem 49

3.1.1 GeneralCharacteristics $\quad 50$

3.1.2 Classification $\quad 50$

3.2 Framework for Discussion $\quad 52$

3.2.1 General Network Assumptions 53

3.2.2 Collisions $\quad 53$

3.2.3 User Population $\quad 54$

3.2.4 Propagation Delay $\quad 55$

3.2.5 Channel Feedback $\quad 55$

3.2.6 Full and Limited Sensing $\quad 56$

$\begin{array}{ll}\text { Summary } & 57\end{array}$

$\begin{array}{ll}\text { Bibliography } & 57\end{array}$

\section{Chapter 4 Fixed Allocation Access Protocols}

4.1 Frequency Division Multiple Access 61

4.1.1 Disadvantages $\quad 62$

4.1.2 Implementation $\quad 62$

4.2 Time Division Multiple Access $\quad 62$

4.2.1 Disadvantages $\quad 63$

4.2.2 Implementation $\quad 64$

4.3 Comparison of FDMA and TDMA 64

4.4 Performance Evaluation $\quad 65$

4.4.1 Frequency Division Multiple Access 65

4.4.2 Time Division Multiple Access 66

4.4.3 StatisticalMultiplexing $\quad 68$ 
$\begin{array}{ll}4.5 \text { Polling Protocols } & 69\end{array}$

$\begin{array}{ll}\text { 4.5.1 Performance Analysis } & 70\end{array}$

$\begin{array}{ll}\text { 4.5.2 Probing } & 71\end{array}$

$\begin{array}{ll}\text { 4.5.3 Adaptive Probing } & 72\end{array}$

4.6 Service Disciplines in Polling Systems 73

$\begin{array}{ll}\text { Summary } & 73\end{array}$

$\begin{array}{ll}\text { Bibliography } & 74\end{array}$

\section{Chapter 5 Contention Protocols}

5.1 General Characteristics $\quad 77$

5.2 ALOHA Protocols 78

5.2.1 Unslotted ALOHA 78

5.2.2 Slotted ALOHA

5.2.3 Disciplined ALOHA 80

5.2.4 Spread ALOHA $\quad 81$

5.3 Performance Analysis of ALOHA Protocols 81

$\begin{array}{ll}\text { 5.3.1 Throughput Analysis } & 82\end{array}$

5.3.2 Average Number of Retransmissions $\quad 84$

5.3.3 Acknowledgments $\quad 85$

5.3.4 Power Capture $\quad 86$

5.3.5 Analyzing the Slotted ALOHA Protocol with Capture 86

5.3.6 Controlled ALOHA $\quad 88$

5.3.7 Asymmetric Traffic Load 88

5.3.8 Scheduling Retransmissions 90

5.3.9 Delay Analysis 93

5.4 Stability Problems in ALOHA Protocols 94

5.4.1 Stability Characterization 95

5.4.2 Dynamic Controls 96

5.5 Feedback Algorithms 96

5.5.1 The Binary Tree Algorithm 97

5.5.2 Analyzing the Tree Algorithm 97

5.5.3 Improving the Tree Algorithm 100

$\begin{array}{ll}\text { 5.5.4 The Splitting Algorithm } & 101\end{array}$

5.5.5 Implementation Considerations 102 
5.6 Carrier Sense Multiple Access 103

5.6.1 CSMA Variations 103

5.6.2 Performance Considerations 104

5.6.3 Implementation Considerations 105

5.6.4 CSMA with Collision Detection 106

5.6.5 Virtual-Time CSMA 107

5.6.6 Busy Tone Multiple Access 108

5.7 Adaptive Protocols 108

5.7.1 The URN Protocol 108

5.8 Hybrid Access Protocols 109

5.8.1 Split Reservation Upon Collision $\quad 110$

5.8.2 Mixed ALOHA Carrier Sense 110

5.8.3 Random Access Polling 110

Summary 111

Bibliography 111

\section{Chapter 6 Spread Spectrum Multiple Access}

6.1 Spread Spectrum Communications 119

6.2 Wideband Versus Narrowband 121

6.2.1 Code Division 121

6.2.2 Time Capture $\quad 121$

6.2.3 Collisions in SSMA Systems 122

6.3 Direct Sequence Spread Spectrum 123

6.3.1 Processing Gain 124

6.3.2 Direct Sequence Code Division Multiple Access 124

6.3.3 Power Control 127

$\begin{array}{ll}\text { 6.3.4 Synchronization } & 128\end{array}$

6.3.5 RAKE Receiver 128

6.3.6 Benefits of DSSS 129

6.4 Frequency Hopped Spread Spectrum 130

6.4.1 Slow and Fast FH 130

6.4.2 Benefits FHSS 131

6.5 Spreading Code Protocols 132

6.5.1 Common Code 132

6.5.2 Transmitter-Directed Codes 132

6.5.3 Receiver-Directed Codes 132

6.5.4 Single Code for Pairs of Users 133 
xii

$\begin{array}{ll}\text { 6.6 CDMA Network Design } & 133\end{array}$

6.6.1 Multirate CDMA 133

6.6.2 CDMA Receivers 134

6.6.3 Multiuser Detection $\quad 134$

6.6.4 Interference Cancellation and Suppression 135

6.6.5 Multicarrier CDMA 135

$\begin{array}{lll}6.7 \text { Performance Analysis } & 136\end{array}$

6.7.1 Queuing Theory Modeling 136

6.7.2 Estimating the Number of Users in DS-CDMA 137

6.8 Comparing FDMA, TDMA, and CDMA 139

$\begin{array}{ll}\text { 6.8.1 Advantages of CDMA } & 139\end{array}$

6.8.2 Disadvantages of CDMA 141

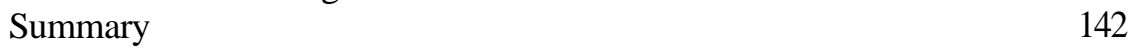

Bibliography 142

\section{Chapter 7 Reservation Protocols}

$\begin{array}{ll}7.1 \text { General Characteristics } & 147\end{array}$

$\begin{array}{ll}7.2 \text { Centralized and Distributed } & 148\end{array}$

$\begin{array}{lll}7.3 \text { Reservation-ALOHA } & 148\end{array}$

7.3.1 Implementation Considerations $\quad 149$

$\begin{array}{lr}\text { 7.3.2 Performance Considerations } & 149\end{array}$

7.4 Packet Reservation Multiple Access $\quad 150$

$\begin{array}{ll}7.5 \text { Dynamic Reservation } & 151\end{array}$

7.5.1 Implementation Considerations $\quad 152$

7.5.2 Performance Considerations $\quad 152$

7.6 Dynamic Reservation Multiple Access 153

$\begin{array}{ll}7.7 \text { Round-Robin Reservation Scheme } & 154\end{array}$

7.8 Split-Channel Reservation Multiple Access 154

7.9 Integrated Access Scheme $\quad 155$

7.10Demand Access Multiple Access $\quad 155$

7.11 Priority-Oriented Demand Assignment 156

7.12 Announced Retransmission Random Access 157

$\begin{array}{ll}\text { 7.13Minislotted Protocols } & 157\end{array}$

7.14Bit Map Access Protocol 158

7.15Broadcast Recognition Access Method $\quad 158$

7.16Multilevel Multiple Access $\quad 159$

$\begin{array}{lr}\text { Summary } & 159\end{array}$

$\begin{array}{ll}\text { Bibliography } & 160\end{array}$ 


\section{Chapter 8 Broadband Wireless Access Protocols}

8.1 The 2.4 GHz IEEE 802.11 Wireless LAN Standard 165

8.1.1 The Distributed Coordination Function 166

$\begin{array}{ll}\text { 8.1.2 Virtual Sensing } & 168\end{array}$

8.1.3 The Point Coordination Function $\quad 170$

8.2 The $5 \mathrm{GHz}$ IEEE 802.11 Wireless LAN Standard 171

8.3 The HIPERLAN Type 1 Wireless LAN Standard 172

8.3.1 The EY-NPMA MAC Protocol 172

$\begin{array}{ll}\text { 8.3.2 Quality of Service } & 175\end{array}$

8.4 The HIPERLAN Type 2 Wireless LAN Standard 175

8.4.1 HIPERLAN Type 2 MAC Protocol 176

8.4.2 HiperLAN Type 2 Frame Format 177

$\begin{array}{ll}\text { 8.4.3 QoS support } & 178\end{array}$

$\begin{array}{ll}\text { 8.5 Home Networks } & 179\end{array}$

8.5.1 HomeRF's Shared Wireless Access Protocol 179

8.5.2 Bluetooth's Access Mechanism 180

$\begin{array}{ll}8.6 \text { Wireless ATM } & 181\end{array}$

8.6.1 Simple Asynchronous Multiple Access 181

8.6.2 Distributed Queuing Request Update Multiple Access $\quad 182$

$\begin{array}{ll}\text { 8.6.3 MASCARA } & 183\end{array}$

8.6.4 WATMnet Access Protocol 184

8.6.5 AWACS Access Protocol 185

$\begin{array}{lll}8.7 \text { Satellite ATM } & 187\end{array}$

$\begin{array}{ll}\text { 8.7.1 Multibeam Systems } & 187\end{array}$

8.7.2 Multifrequency TDMA 188

$\begin{array}{ll}8.8 \text { Wireless Local Loop } & 189\end{array}$

$\begin{array}{ll}\text { 8.8.1 MMDS } & 189\end{array}$

$\begin{array}{ll}\text { 8.8.2 LMDS } & 190\end{array}$

8.8.3 Access Methods in LMDS 190

$\begin{array}{ll}8.9 \text { IMT-2000 } & 190\end{array}$

8.9.1 Coverage Areas and Data Rates 191

8.9.2 CDMA Proposals 191

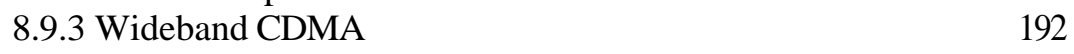

8.9.4 Time-Duplexed CDMA 193

8.9.5 CDMA2000 193

8.9.6 TDMA Proposals 194

$\begin{array}{lr}\text { Summary } & 195\end{array}$

$\begin{array}{ll}\text { Bibliography } & 195\end{array}$ 


\section{Chapter 9 A Generalized Broadband Wireless Access Protocol}

9.1 Protocol Description 199

$\begin{array}{ll}9.2 \text { Protocol Evaluation } & 203\end{array}$

9.3 Analysis of Randomized Slotted ALOHA 204

9.3.1 Throughput Analysis 205

9.3.2 Stability Analysis 206

9.4 Analysis of the Generalized Protocol 211

$\begin{array}{ll}\text { 9.4.1 Throughput Analysis } & 212\end{array}$

$\begin{array}{ll}\text { 9.4.2 Delay Analysis } & 214\end{array}$

$\begin{array}{ll}9.5 \text { Performance Comparison } & 221\end{array}$

$\begin{array}{ll}9.6 \text { Traffic Load Balancing } & 223\end{array}$

9.6.1 Protocol Description 226

9.6.2 Simulation Results $\quad 229$

$\begin{array}{ll}9.7 \text { OPNET Simulation Models } & 232\end{array}$

9.8 OPNET Models for Generalized Protocol 233

9.8.1 User Model for Base Station 233

9.8.2 User Model for User with Periodic Traffic 234

9.8.3 Process Model for Base Station $\quad 234$

9.8.4 Process Model for User with Periodic Traffic 236

9.9 OPNET Models for Traffic Load Balancing 238

9.9.1 User Model for Base Station 239

9.9.2 User Model for User with Periodic Traffic 239

9.9.3 Process Model for Base Station 239

9.9.4 Process Model for User with Periodic Traffic 239

$\begin{array}{ll}\text { 9.10Simulation Time } & 240\end{array}$

9.11Formal Verification of Generalized Protocol 240

$\begin{array}{ll}9.11 .1 \text { Correctness } & 241\end{array}$

$\begin{array}{ll}\text { 9.11.2 Safety } & 241\end{array}$

9.11.3 Liveness $\quad 242$

Summary 243

Bibliography 244

\section{Appendix Queuing Theory Primer}

$\begin{array}{ll}\text { A.1 The Poisson Process } & 247\end{array}$

$\begin{array}{ll}\text { A.2 Little's Theorem } & 248\end{array}$

A.3 The Single Server Queue $\quad 249$

A.3.1 M/G/1 Queue 250 
A.3.2 M/M/1 Queue

A.3.3 M/D/1 Queue

251

A.4 Conservation Laws

Acronyms

253

About the Author

259

Index

261 
"The wireless music box has no imaginable commercial value. Who would pay for a message sent to nobody in particular?"

- David Sarnoff's associates in response to his urging for investment in radio, 1920s.

\section{Preface}

The last century has seen the introduction of many types of wireless communication services which have become the cornerstone of modern telecommunications. Broadcast radio and television have dramatically changed our perception and understanding of the world we live in. The use of cellular phones has brought about the freedom to roam to different vicinities and yet communicate. More importantly, the success of cellular wireless service in support of vehicular and pedestrian users has created a pressing demand for such wireless service to be coupled with emerging broadband wireline infrastructure involving the Internet, thereby extending the benefits of multimedia services from the home and business environments, and heralding in a new era of anyone, anywhere, anytime, any media communications. As we start the new millennium, such exciting wireless communication technologies are already evolving and expanding at a phenomenal pace. Third-generation personal communication systems have been planned while high-speed wireless asynchronous transfer mode (ATM) networks and wireless Internet connectivity are the major focus of recent research efforts. These broadband networks aim to provide integrated, packet-oriented, transmission of text, graphics, voice, image, video, and computer data between individuals as well as in the broadcast mode.

In determining the performance of broadband wireless systems, many factors come into play. These factors are heavily dependent on the characteristics of the wireless channel such as signal fading, multipath distortion, limited bandwidth, high error rates, rapidly changing propagation conditions, mutual interference of signals, and the vulnerability to eavesdrop and unauthorized access. Moreover, the performance observed by each individual user in the network is different and is a function of its location as well as the location of other interacting users. Issues related to connection control and traffic management must also be addressed. The 
biggest challenge is to support real-time applications by providing bandwidth on demand (i.e., adequate quality of service) seamlessly across wireless and wireline networks.

One of the crucial elements of these advanced wireless systems is the access protocol, which defines the way a common bandwidth resource (the communication channel) is shared among contending users and hence, determines the overall performance of the system. For broadband wireless networks, the access protocol must ensure efficient and timely (on-demand) access to multirate applications with different communications requirements. In addition, the protocol is required to operate with the difficult constraints posed by moving users, dynamic variation in traffic patterns, and highly sensitive wireless links. Issues related to the connection control and traffic management of widely disparate traffic streams must also be addressed. The biggest challenge is to support real-time applications by providing bandwidth on demand (i.e., adequate quality of service) seamlessly across wireless and wireline networks.

Many access schemes currently deployed in mobile cellular networks employ a fixed frame structure. For instance, time division multiple access (TDMA) is a popular choice for several digital cellular systems such as GSM, IS-54, PDC and for wireless personal communication systems such as DECT, PHS, WACS. However, to cater for packetized multimedia traffic, the selection of a suitable TDMA frame structure is a not an easy task since it is unlikely that the exact mix of applications will either be known beforehand or remain stable. If time slots (that constitute a TDMA frame) are chosen to match the largest message lengths, slot times that are under-utilized by short messages must be padded out to fill up the slots. On the other hand, if shorter slot sizes are used, more overhead per message results. For some TDMA schemes, long frames are necessary in order to maximize the bandwidth utilization at high traffic load but this is done at the expense of increasing the delay at low load. To accommodate the greater levels of uncertainty created by the mixing of a wide assortment of applications, multiple access schemes supporting multimedia services should strive to achieve more flexible bandwidth sharing by allowing users to seize variable amounts of bandwidth on demand.

The access technique in spread spectrum and wideband code division multiple access (CDMA) networks usually refers to the ability of certain kinds of signals to coexist in the same frequency and time space with an 
acceptable level of mutual interference. The use of pseudorandom waveforms in a wireless network is motivated largely by the desire to achieve good performance in fading multipath channels and the ability to operate multiple links with pseudo-orthogonal waveforms using spread spectrum multiple access. A number of hybrid CDMA, multicarrier and orthogonal frequency division multiplexing (OFDM) schemes have been proposed for high-speed wireless communications. Multicarrier schemes that employ parallel signaling methods offer several significant advantages over conventional single carrier systems including protection against dispersive multipath channels and frequency-selective fading. With appropriate signal processing, these systems can achieve the equivalent capacity and delay performance of single carrier systems without the need for a continuous spectrum. Although the technology is promising, many technical challenges need to be overcome before spread spectrum-based systems can efficiently accommodate the high and variable bit rates demanded by broadband multimedia services.

The purpose of this book is to discuss the design and development of wireless access protocols with emphasis on how such protocols can efficiently support disparate classes of multimedia traffic. Besides a comprehensive introduction and survey to the evolution of wireless access protocols, many important protocols that are deployed or experimented in various broadband wireless environments (e.g., wireless ATM, broadband satellite networks, mobile cellular and personal communication systems, wireless local loops, wireless local area and home networks) are also covered.

I have attempted to make the book accessible to a wide audience. It serves as an excellent bridge between novice readers who wish to know more about the subject and advanced readers who are undertaking research in this area. While engineering aspects are discussed, the emphasis is on the physical understanding of access protocols, from basic operations to the latest innovations. To this end, mathematical treatment is kept to a minimum and most of the fundamental concepts are explained based on intuition and insights, supplemented by numerous illustrative figures. In addition, these concepts are expressed succinctly and concisely. Wherever possible, important references that make major contributions to the field are included for interested readers to investigate further. Latest updates and useful Web resources are also posted at the book's Web site. Readers are 
encouraged to send an email to bennybing@ieee.org to request for the URL. Constructive feedback on any aspect of the book is always welcomed.

The chapters in this book are organized as follows. Chapter 1 addresses several technical considerations related to wireless network operation which may have a direct impact on the feasibility of implementing multiple access protocols. In Chapter 2, the key issues for communication among distributed users who share and contend for a single broadcast channel are identified. The fundamental characteristics of multimedia traffic and the associated networking requirements are also reviewed. Chapter 3 defines the multiple access problem and focuses on the ideas and core concepts behind the major protocols that have been proposed over the years. It serves as a guide for those who wish to design new protocols that meet specific applications. This is followed a broad survey of existing multiple access strategies in Chapters 4 to 7 . The strategies are categorized under fixed assignment, contention, reservation, and spread spectrum multiple access. Chapter 8 discusses several state-of-art broadband multiple access schemes that are applied in emerging high-speed wireless networks, including the IEEE 802.11, HiperLAN, HomeRF, Bluetooth, wireless ATM, satellite ATM, LMDS, and IMT-2000. This chapter provides a valuable resource for network designers who wish to understand the access procedures of these advanced networks. The complete design methodology of a generalized broadband wireless access protocol is described in Chapter 9. The performance is analyzed, simulated, and validated. The OPNET simulation models and protocol verification procedures are particularly useful for researchers working on multiple access protocol design. Finally, an extensive list of references allows readers to explore the latest research challenges in this highly fascinating subject. The references are separated according to the topics discussed in each individual chapter. The myriad of access protocols proposed over the last three decades is clear evidence of how important this field has become and will continue to be a fertile ground for research in the years ahead.

Writing a rapidly evolving technical subject is never an easy task. I am especially indebted to several individuals who have provided valuable feedback and personal insights which helped to refine certain aspects of the book. These include Professor Robert Gallager (Massachusetts Institute of Technology), Professor Leonard Kleinrock (University of California at Los Angeles), and Dr. Jouni Mikkonen (Nokia). At the same time, I would like to acknowledge the comments from the reviewers as well as the 
encouragement, patience, and help from Patricia Lincoln and Alex Greene from Kluwer Publishers. Special thanks also go to the production staff for an excellent job in producing the manuscript. Finally, I am grateful to my former thesis advisor, Professor Regu Subramanian at the Nanyang Technological University who first introduced me to this immense subject of multiple access communications.

Benny Bing Maryland, USA 